possible to provide them in a region containing a number of such orbits. If there is movement of population from the congested cities, the 'overspill' is likely to be better accommodated and better employed if it is kept in close relation to a regional or sub-regional centre than if it is dispersed to independent new towns. Industrial development should be viewed on a regional scale, taking fully into account the existence of the traditional regions, and aiming at introducing new complexes of industry into these existing regions. The broadsheet points to several factors which increase the mobility of industry, but finally emphasizes the difficulty of applying the general principles indicated. Usually, in practice, the decision must be a balance between economic and social considerations, and close co-operation between the central Government and industrialists is needed.

\section{Selection of Medical Students}

IN an earlier issue (Nature, 154, 315, Sept. 9, 1944) the possibility that intelligence tests might be used as aids in the selection of candidates who wish to undergo a medical training was discussed in relation to the proposals of the Goodenough Committee on Medical Schools and the Planning Committee of the Royal College of Physicians for the selection of medical students by personal interview rather than by examinations alone. Drs. O. G. Edholm and Q. H. Gibson (The Lancet, 294, Aug. 26, 1944) have now published the results of their work on examination results as intelligence tests. This work was done at Queen's University, Belfast, where second-year medical students have, for the past three years, carried out "an intelligence test, using Raven's Progressive Matrices" (J. C. Raven, Progressive Matrices, London, 1938). The scores obtained were compared with examination results. The students included 20 per cent women, and the average age of both men and women students was $19 \frac{1}{2}$ years. These authors conclude that "one of the most striking and important points which emerges from these results is the high mental ability of the average medical student, as measured by the matrix test". They quote the report of the Planning Committee of the Royal College of Physicians as saying that the average medical student of to-day is lacking in initiative and curiosity, with poor ability to arrange and interpret facts and little precision in the use of words. "If we accept this statement," these authors comment, "either unusually great ability is necessary to avoid these faults, or they are not primarily due to any lack of intelligence." Other critics of the mental ability of the average medical student might take this statement to heart.

More pertinent to the selection of future medical students is the conclusion of Drs. Edholm and Gibson that "a fairly rigid process of selection has already been applied by the time the student reaches his second year". This would seem to confirm the view expressed in Nature (loc. cit.) that "Selection can . . . be imposed too early, and the value of the natural selection of the medical school and the hospital can be underestimated". Discussing the question whether the matrix test would be valuable for the selection of medical students, these authors conclude that the results of previous examinations form a more reliable index of results in future ones. They find no reason to think that the medical students of Queen's University are not representative of the intelligence of medical students generally; but they think that further work should be done to show whether their results are generally applicable. R. G. Inkster (Roy. Acad. Med., Ireland, Sect. Anat. and Physiol., March Meeting, 1944) obtained results similar to theirs; but he used an entirely different intelligence test. The authors do not wish to imply, however, that success in examinations is the only criterion of the satisfactory student.

\section{Spectrographic Discussion Group}

THE Spectrographic Discussion Group was formed in 1941 as a result of approaches made to the various users of spectrographic equipment in the Glasgow area. It was considered that, in view of the extent to which industrial concerns and Government departments were applying spectrographic methods of analysis and the very rapid developments which were taking place in this branch of science, it would be of value if those directly interested in spectrography were able to meet at intervals and discuss the various problems which arose in the course of their work. Further, it was considered advisable that representa. tives of the principal technical institutions and of manufacturers of spectrographic equipment should have the opportunity to attend these discussions. The fundamental policy of the Group required the free interchange of ideas and co-operation in tackling any problems which arose as a result of discussion. Although originally confined to members in the Glasgow area, the success of the Group was such that, in a relatively short time, members representing concerns in Aberdeen, Sheffield, London and other parts of the country were admitted. Meetings of the Group are held in the Royal Technical College, Glasgow, at intervals of approximately six weeks. The chairman is Mr. S. D. Steele, of Babcock and Wilcox, Ltd., Renfrew, Scotland. It has always been considered of first importance that the nature of these discussions be informal, and that in no sense should the Group acquire the character of a society. In this respect it has been found necessary to limit membership to those directly interested in spectrography and also to control membership by invitation. The success of the Group and the progress made have been so marked that it is felt that groups of a similar nature established throughout Britain would be most beneficial.

\section{Long Ashton Research Station}

THE annual report of the Long Ashton Research Station for 1943 has now been published. Several important changes in senior staff appointments mark the period covered, for Prof. B. T. P. Barker, director of the Station during its first forty years, has retired, being succeeded by Prof. T. Wallace, while Mr. A. W. Ling, though still remaining chief agricultural advisory officer in the Bristol Province, has been appointed principal of the Seale Hayne Agricultural College, Devon. The research work undertaken dur. ing the year continued to be closely concerned with current problems of the food production programme of the Ministry of Agriculture, and many useful results were obtained, only a few of which can be mentioned here. Tests made with apples, swedes, carrots and potatoes showed that $\frac{1}{2} 1$ per cont naphthalene-acetic acid exerts a delaying action on bud-growth, a fact which should prove of practical importance in preventing sprouting of stored potatoes, while an allied compound, naphthoxyacetic acid, sprayed at the rate of twenty parts per million, had a stimulating effect and increased the yield of Tardive de Leopold strawberries. Outstanding results have 